\title{
Information as a determinant criterion in the acceptance of fermented yam-based ice cream
}

\author{
Nádia Nara BATISTA ${ }^{1}$, Cíntia Lacerda RAMOS ${ }^{2,3}$, Josiane Ferreira PIRES ${ }^{2}$, \\ Disney Ribeiro DIAS ${ }^{1}$, Rosane Freitas SCHWAN ${ }^{2 *}$ (D)
}

\begin{abstract}
The aim of this study was to evaluate the influence of information on the acceptability of fermented yam-based ice cream, as well as its sensorial profile. For this, the acceptance and check all that apply (CATA) tests were performed in two sessions by 102 tasters. In the first session, consumers received only brief information about the ice cream preparation. Additional information about the healthy contribution of the product was provided to the consumers in the second session. In the acceptance test, significant differences between the sessions were observed $(p<0.05)$ for the flavor attribute. Information on health benefits contributed by a reduction of "dislike moderately" and "dislike very much" classes (mainly 50-80\%), and an increase of "like slightly" and "like moderately" classes (mainly 30-50\%) in the acceptability test in the second session. The first session, the ice cream was related to coconut water and acid flavors and sandy texture, while in the second session it was described as yogurt flavor and creamy texture. There was a tendency to assign more pleasant characteristics to the second session. Therefore, the ice cream acceptance and sensory profile described by consumers were affected by the provided information, especially for the male group.
\end{abstract}

Keywords: acceptability test; CATA; health benefits; sensory analysis.

Practical Application: The kind of information can be a determining factor in the acceptability of the final product.

\section{Introduction}

Lactose intolerance affects approximately $75 \%$ of the world's population, with $15 \%$ of people from northern Europe, $80 \%$ of African and Latins, and 100\% of Indians from America and Asia (Swagerty et al., 2002; Szilagyi, 2015). The malabsorption of lactose by the intestine occurs due to the deficiency of lactase production by the individual resulting in gastrointestinal symptoms, such as watery stools, swelling, and abdominal pain (Swagerty et al., 2002; Szilagyi, 2015). The use of cereals, roots, and tubers has been an interesting alternative to the production of lactose-free products by food industries. Currently, the market offers vegetable-based beverages elaborated mainly from rice, oats, and soy (Sethi et al., 2016).

The yam is a tuber belonging to the Dioscoreacea family, composed of carbohydrates, essential amino acids, minerals, vitamins, and bioactive compounds such as diosgenin, allantoin, and dioscorin (Wanasundera \& Ravindran 1994). According to FAO (Food and Agriculture Organization of the United Nations, 2013), approximately 62 million tons of yam are annually produced and around 6.7 million tons are lost during post-harvest treatment. Yam processing is an alternative to reduce waste and increase the consumption of this tuber by the population.

The consumer market has shown a growing trend for foods that contribute to health and well-being (Vicentini et al., 2016). To satisfy consumer demand, the researchers and food industry have focused efforts on the development of novel and alternative products (Ayar et al., 2018; Borrin et al., 2018; Gabbi et al., 2018; Kalicka et al., 2019; Vital et al., 2018). In this sense, the elaboration of fermented foods has been highlighting due it improving nutritional and sensorial quality of foods in addition to prolonging the shelf life of the products (Bourdichon et al., 2012; Holzapfel et al., 1995).

One of the essential tools during the elaboration of a new product is the sensorial evaluation (Penna, 1999). Sensory perception is a dynamic process that allows characterizing the sample and assessing its acceptability by consumers. Among the sensory methods, the acceptance test is commonly used to obtain information on how much the consumer liked and disliked the sample, based on the hedonic scale structured with nine points (Ayar et al., 2018; Freire et al., 2017; Stone \& Sidel, 1985).

The check all that apply (CATA) test has been widely used for optimizing food formulations and characterizing new products (Alencar et al., 2019; Oliveira et al., 2017; Santos et al., 2015; Torres et al., 2017). It offers a quick, simple, and easy procedure to describe the sample by consumers when compared with other methods (Ares et al., 2010; Valentin et al., 2012).

During the sensorial analysis, several factors, such as those related to the product, consumer, and environment may influence the consumers' evaluation. The aim of this work was to study 
the influence of product information in the acceptance as well as the sensorial profile of fermented yam-based ice cream.

\section{Materials and methods}

\subsection{Fermented yam-based ice cream elaboration}

The fermented yam-based ice cream elaboration was performed in three steps. First, a yam-based medium was prepared using approximately $2 \mathrm{~kg}$ of washed, peeled, and sliced yam (purchased from a local market in Lavras city, Minas Gerais state, Brazil). The yam slices were preheated at $60^{\circ} \mathrm{C}$ for $10 \mathrm{~min}$. The yam-based medium was prepared adding $40 \%(\mathrm{w} / \mathrm{v})$ of preheated yam, $60 \%(\mathrm{v} / \mathrm{v})$ of mineral water, and $1 \%(\mathrm{w} / \mathrm{v})$ of carboxymethylcellulose. The medium was pasteurized at $65^{\circ} \mathrm{C}$ for $30 \mathrm{~min}$.

The second step consisted of lactic acid fermentation using Leuconostoc lactis CCMA0415 strain (Culture Collection of Agricultural Microbiology, UFLA, Brazil), due its amylase and phytase activity, fast acidification, and growth in the yam medium (data not shown). The bacteria were previously grown in MRS medium (Merck, Darmstadt, Germany) at $35^{\circ} \mathrm{C}$ for $24 \mathrm{~h}$, and inoculated into the $300 \mathrm{~mL}$ yam-based medium at a population of $10^{7} \mathrm{CFU} / \mathrm{mL}$. The fermentation was carried out at $35^{\circ} \mathrm{C}$ for $6 \mathrm{~h}$.

Following fermentation, the third step was the ice cream elaboration using the fermented yam dough. Stabilizer (Liga neutra, Selecta, Brazil) $0.6 \%(\mathrm{w} / \mathrm{v})$, glucose $1.11 \%(\mathrm{w} / \mathrm{v})$, and sucrose $10 \%(\mathrm{w} / \mathrm{v})$ were added to the fermented dough. The mixture was homogenized and maturated for $24 \mathrm{~h}$. Then, $0.6 \%(\mathrm{w} / \mathrm{v})$ of emulsifier (Emustab Selecta, Brazil) was added to the mixture, which was beaten in an ice cream maker for $10 \mathrm{~min}$ and frozen at $-20^{\circ} \mathrm{C}$ (Jimenez-Flores et al., 1992).

\subsection{Sensorial analysis}

The sensorial analysis of the fermented yam-based ice cream was conducted at the Federal University of Lavras (Lavras-MG) by a panel of 102 consumers, composed of 58.82\% female and $41.18 \%$ male, aged $18-60$ years. The sample was offered in plastic cups $(50 \mathrm{~mL})$ containing approximately $5 \mathrm{~g}$ of ice cream.

The sensorial analysis of the ice cream was carried out in two sessions. In the first session, consumers received the following information, "You are getting a sample of lactose-free ice cream." In the second session, the information was, "You are receiving a sample of lactose-free ice cream, elaborated from the yam. The development of this product aims to increase the diversity of lactose-free functional foods through the elaboration of a fermented yam product. Yams consist of carbohydrates, essential amino acids, minerals, and vitamins (thiamine, riboflavin, niacin, vitamin $\mathrm{A}$, and ascorbic acid), in addition to bioactive compounds such as diosgenin, allantoin, and dioscorine that can act to improve total cholesterol levels, LDL, HDL, triglyceride, glucose, and has an anticancer effect. The regular consumption of this food may be effective in controlling metabolic diseases (cholesterol, diabetes, and obesity), inflammation, and cancer."

After providing the information about the product, the acceptance test followed by the CATA test were performed. In the acceptance test, the consumers evaluated the taste, aroma, appearance, texture, and overall impression attributes in each session. The ice cream was rated in terms of how much they liked and disliked each attribute using the structured hedonic scale of nine points ( 1 - dislike extremely, 2 - dislike very much, 3 - dislike moderately, 4 - dislike slightly, 5 - neither like nor dislike; 6 - like slightly, 7 - like moderately, 8 - like very much, 9 - like extremely) (Stone \& Sidel, 1985). This information can be important to predict or explain the market response (García-Gómez et al., 2019)

In the CATA test, a focus group was carried out to define the characteristics related to ice cream. Ten sensory characteristics: coconut water, sweet, fruity, green apple, mango, sour, nut, natural yogurt, sandy, and creamy, related to taste and texture attributes were previously defined by a group of ten tasters. During the sensorial analysis, the consumers selected those attributes that they considered more appropriate to describe the ice cream. The sensorial analysis was conducted with the approval of the Ethics Committee (CAAE 64258116.5.0000.5148) (Federal University of Lavras).

\subsection{Statistical analysis}

The normality of data was tested using the Shapiro-Wilk test. Then, the attributes score for the acceptance test were submitted to Friedman's analysis using the SPSS software. Significant differences were observed when $p<0.05$.

The influence of gender on the acceptability of the ice cream was performed using a Gabriel biplot in which the scores variation given by male and female audiences during the two sessions was evaluated. The sensorial profile of ice cream was obtained by CATA and the data were analyzed by Principal Component Analysis (PCA) using a correlation matrix (11 rows, 2 columns). Pearson (n) was applied to standardization the variables. The taste and texture attributes were used to characterize ice cream samples in the two sessions of sensorial analysis (Hammer et al., 2001). Both analyses used the XLSTAT software.

\section{Results and discussion}

The human preference for certain foods is related to the chemical and physical properties imparted by the ingredients and the processes used in manufacture and handling (Marshall et al., 2003).

The ice cream was prepared from the fermentation of the yam by Leuconostoc lactis CCMA 0415 . The fermentation process contributes to increasing minerals content and digestibility due to reduction of starch and proteins in addition to improving the product safety by $\mathrm{pH}$ decrease to 4.0 and organic acids production such as lactic acid $(0.2 \% \mathrm{~m} / \mathrm{v})$. The sensorial analyses were performed using acceptance and CATA tests in two sessions with 102 consumers. In the acceptance test, the evaluated attributes were appearance, aroma, taste, texture, and overall impression.

The acceptability of the fermented ice cream showed different results for the first and second sessions. In the first session (Figure 1) the attributes appearance, aroma, flavor, texture, and overall impression were predominantly classified by consumers as "like very much" (23.50\%), "neither like nor dislike" (28.43\%), "like slightly" (24.50\%), "dislike slightly" (21.56\%), and "like slightly" (23.52\%), respectively. In the second session, the same 


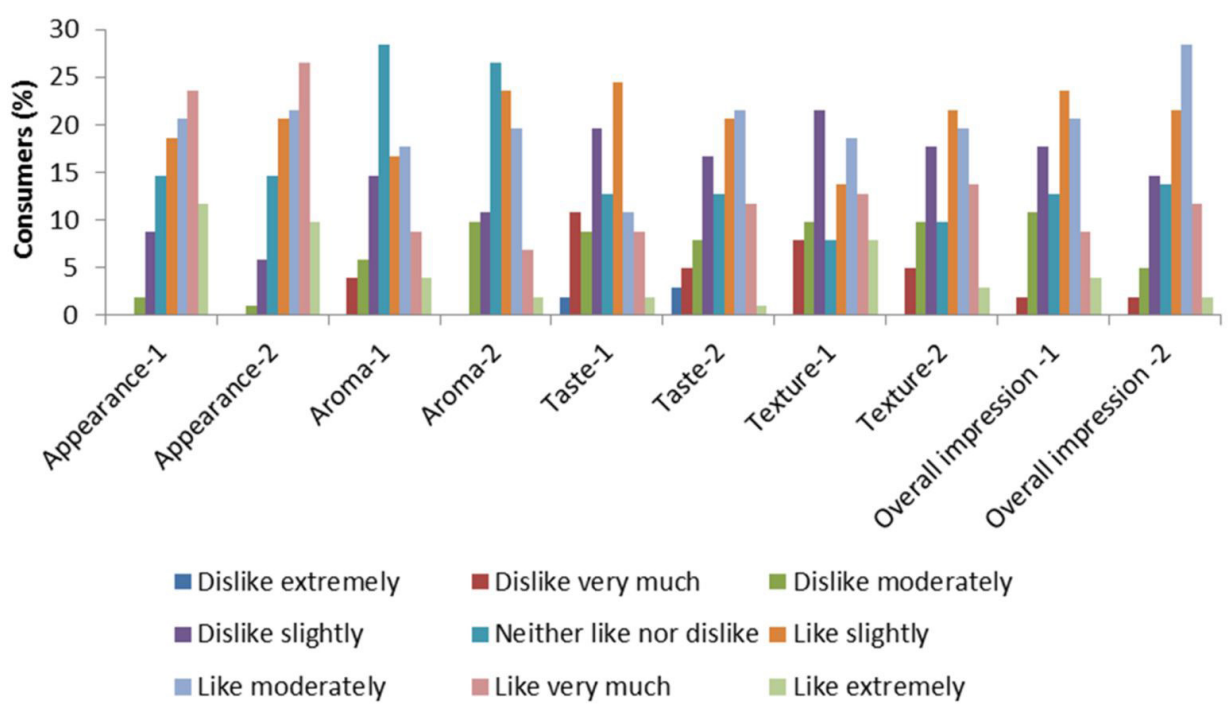

Figure 1. Fermented yam-based ice cream acceptability for the sensorial attributes in the two sessions. Attributes followed by 1 refer to the first session and attributes followed by 2 refer to the second session.

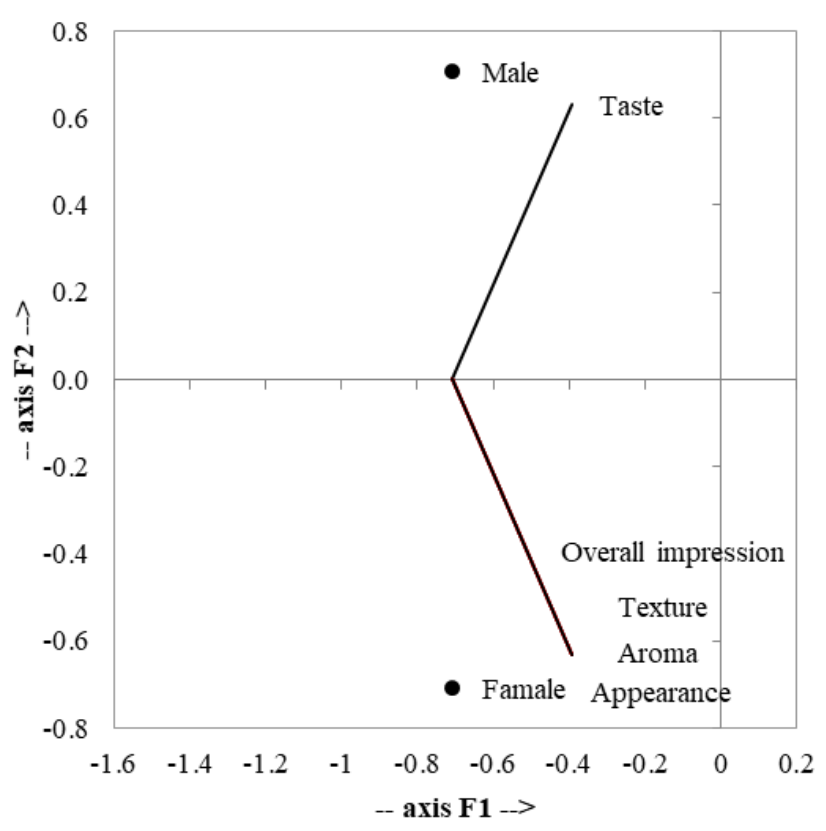

Figure 2. Influence of gender on fermented yam-based ice cream acceptability evaluated by Gabriel plot using PCA data.

attributes were classified as "like very much" (26.47\%), "neither like nor dislike" (26.47\%), "like moderately" (21.56\%), "dislike slightly" (21.56\%) and "like moderately" (28.43\%), respectively. According to the data, the flavor attribute was significantly different $(p<0.05)$ between the two sessions. Trondsen et al. (2004) described that when the food is related to beneficial functions to health, the flavor is the main attribute influencing the consumers' perception. The present study showed the male public was the more influenced group by the information provided (Figure 2). Furthermore, the classification of flavor attribute of ice cream also changed from the first to the second session, showing a reduction of $50-80 \%$ in "dislike very much" class and an increase of $100 \%$ in the "like moderately" class (Figure 3 ).

Comparing the acceptability of ice cream in the two sessions, it was observed a reduction of 50-80\% in the "dislike very much" class for appearance and overall impression attributes, decreasing the rejection of the product. Further, the "like very much" class, for the appearance attribute, and "like moderately", for the overall impression attribute, showed an increase in acceptability of $11-20 \%$. The aroma had a $100 \%$ reduction in the "dislike very much" class, an increase of 30-50\% for the "like slightly" class, a $21-40 \%$ reduction in the "dislike very much" class, and an increase of $51-70 \%$ for the "liked slightly" class. These data show an improvement in acceptance in the second session when more information about functional benefits of the food was provided.

The variation in the response of consumers to the acceptability of fermented yam-based ice cream was more marked for males. This variation probably occurred due to the awareness of the male population about the influence of dietary habits on the development of not transmissible chronic diseases (NCD) that, in general, is a concern only of the female population (Castres, 2015; Deeks et al., 2009). In 2015, it was estimated there were 40 million deaths from NCD. The main NCDs are cardiovascular diseases (17.7 million), cancers (8.8 million), respiratory diseases (3.9 million), and diabetes (16 million), affecting males more than females. The main factors related to the development of NCDs are smoking, alcohol consumption, high blood pressure, and obesity (World Health Organization, 2017). Thus, from the information about the benefits of yam consumption, a reduction in the attribution of the "dislike moderately" and "dislike very much" classes was observed that negatively influence the acceptability of the product. Consequently, increases of the "like slightly" and "like moderately" classes were observed.

The sensorial description of ice cream was obtained by CATA using the flavor attributes coconut, sweet, fruity, green apple, 


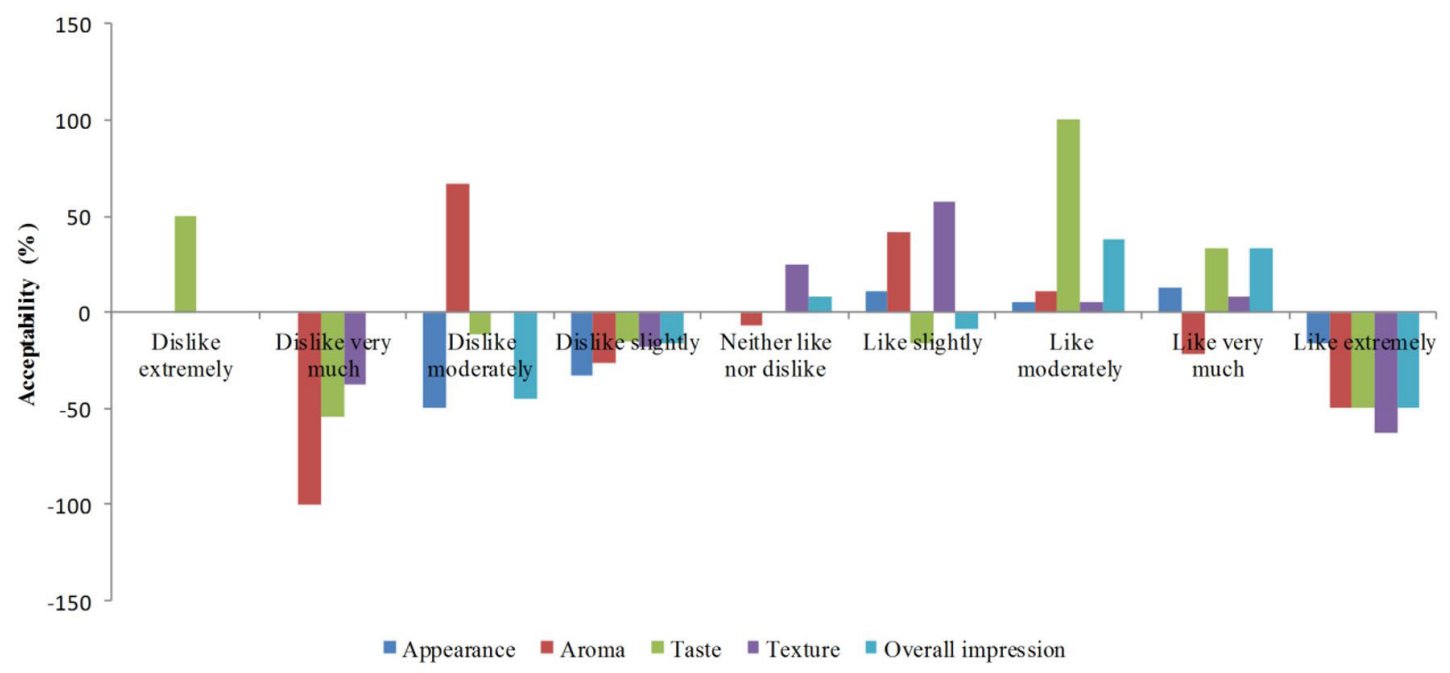

Figure 3. Percentage of acceptability of the yam-based ice cream by the consumers from first session to second session

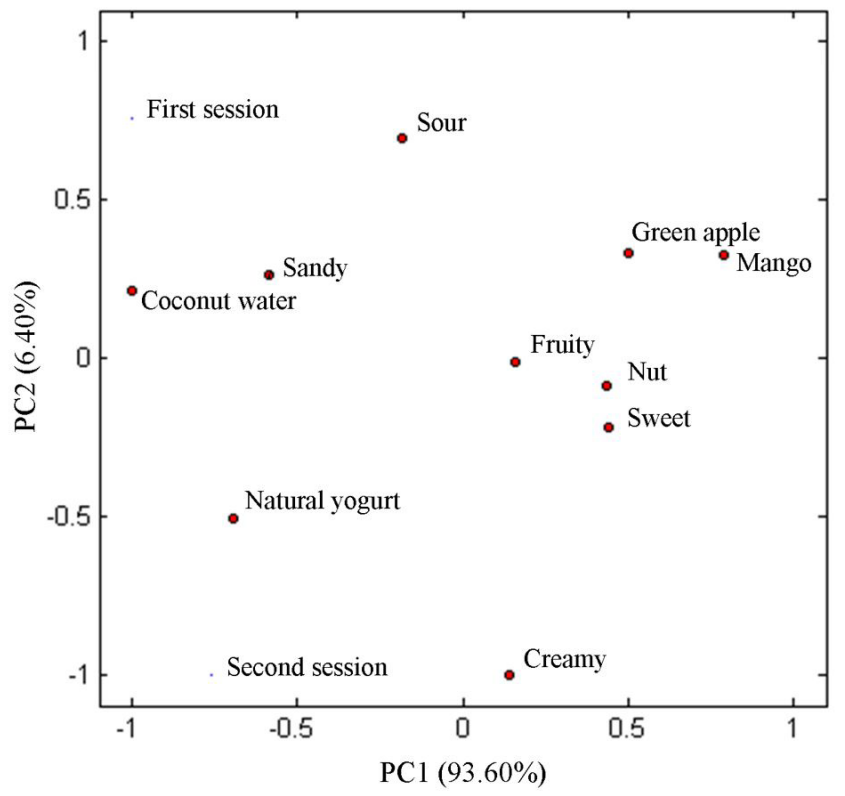

Figure 4. Principal Component Analysis of the sensorial descriptive attributes of fermented yam-based ice cream evaluated by CATA in the two sessions.

mango, sour, nut, and natural yogurt; and texture attributes sandy and creamy. CATA is a fast alternative to a descriptive test as it does not require extensive training with consumers. It employs a predefined list of attributes in which consumers select the attributes they consider most appropriate to describe the sample (Valentin et al., 2012).

The PCA was performed using the CATA results to verify descriptive differences between the two sessions (Figure 4). The components represented $100 \%$ of the total variation of the data. Component 1 corresponded to $93.60 \%$ and component 2 corresponded to $6.40 \%$ of the total variability. It is possible to observe a correlation between the first session and the attributes coconut and acid flavors and sandy texture positioned on the negative side of $\mathrm{PC} 1$ and positive side of $\mathrm{PC} 2$. On the other hand, on the negative side of PC2, the second session was more correlated to yogurt flavor and creamy texture. Therefore, it is clear to an observer a tendency to associate more pleasant characteristics to the second session in relation to the first session. It seems that green apple, nut, sweet, mango, and fruity flavors were not influenced by the provided information because these attributes were not correlated with any session (Figure 4).

The information about product composition as well as possible benefits that product's components can provide to the consumer's health, positively influence the acceptance and the sensory description of the food. Healthy food, convenience food products and sustainable products are important criterion to be considered by industries when launching a new product on the market.

\section{Conclusion}

The information about the product composition as well as the possible benefits that the yam consumption can provide to the consumer's health positively influenced the acceptance and the sensory description of the ice cream. The flavor attribute differed significantly between the two sessions, showing to be the determining attribute to the acceptability of the final product. Further, the male group was the most influenced consumers by the provided information. Fermented yam-based ice cream was characterized as a promising lactose-free product for the food industry as it showed high acceptability and yogurt and creamy sensorial description by the consumers. The information about health promotion may increase the acceptability of alternative and novel food products by the consumers, especially males. In addition to functionality of yam-based product, the ice cream texture is also an important factor to promote the consumption of this product in world-wide. The yam-based ice cream showed a creaminess which consumer liked slightly, however; some processing adaptations may be optimized to further improve the acceptability of the final product. 


\section{Acknowledgements}

The authors thank the Brazilian agencies Conselho Nacional de Desenvolvimento Científico e Tecnológico do Brasil (CNPq), Fundação de Amparo à Pesquisa do Estado de Minas Gerais (FAPEMIG) and Coordenação de Aperfeiçoamento de Pessoal de Nível Superior (CAPES). The authors gratefully acknowledge the anonymous referees for their comments and constructive suggestions for improving the quality of this manuscript.

\section{References}

Alencar, N. M. M., Ribeiro, T. G., Barone, B., Ana, P. A. B., Aline, T. B. M., \& Behrens, J. H. (2019). Sensory profile and Check-All-ThatApply (Cata) as tools for evaluating and characterizing syrah wines aged with oak chips. Food Research International, 124, 156-164. http://dx.doi.org/10.1016/j.foodres.2018.07.052. PMid:31466634.

Ares, G., Deliza, R., Barreiro, C., Giménez, A., \& Gámbaro, A. (2010). Comparison of two sensory profiling techniques based on consumer perception. Food Quality and Preference, 21(4), 417-426. http:// dx.doi.org/10.1016/j.foodqual.2009.10.006.

Ayar, A., Siçramaz, H., Öztürk, S., \& Yilmaz, S. Ö. (2018). Probiotic properties of ice creams produced with dietary fibres from by-products of the food industry. International Journal of Dairy Technology, 71(1), 174-182. http://dx.doi.org/10.1111/1471-0307.12387.

Borrin, T. R., Georges, E. L., Brito-Oliveira, T. C., Moraes, I. C. F., \& Pinho, S. C. (2018). Technological and sensory evaluation of pineapple ice creams incorporating curcumin-loaded nanoemulsions obtained by the emulsion inversion point method. International Journal of Dairy Technology, 71(2), 491-500. http://dx.doi.org/10.1111/14710307.12451.

Bourdichon, F., Casaregola, S., Farrokh, C., Frisvad, J. C., Gerds, M. L., Hammes, W. P., Harnett, J., Huys, G., Laulund, S., Ouwehand, A., Powell, I. B., Prajapati, J. B., Seto, Y., Schure, E. T., van Boven, A., Vankerckhoven, V., Zgoda, A., Tuijtelaars, S., \& Hansen, E. B. (2012). Food fermentations: microorganisms with technological beneficial use. International Journal of Food Microbiology, 154(3):87-97. https:// doi.org/10.1016/j.ijfoodmicro.2011.12.030.

Castres, P. (2015). Informed food choices for healthier consumers. Brussels: The European Consumer Organisation.

Deeks, A., Lombard, C., Michelmore, J., \& Teede, H. (2009). The effects of gender and age on health related behaviors. BMC Public Health, 9(1), 1-8. http://dx.doi.org/10.1186/1471-2458-9-213. PMid:19563685.

Food and Agriculture Organization of the United Nations - FAO. (2013). Commodity balances - crops primary equivalent. Rome: FAO. Retrieved from http://www.fao.org/faostat/en/\#data/BC

Freire, A. L., Ramos, C. L., Souza, P. N. C., Cardoso, M. G., \& Schwan, R. F. (2017). Nondairy beverage produced by controlled fermentation with potential probiotic starter cultures of lactic acid bacteria and yeast. International Journal of Food Microbiology, 248, 39-46. http:// dx.doi.org/10.1016/j.ijfoodmicro.2017.02.011. PMid:28242421.

Gabbi, D. K., Bajwa, U., \& Goraya, R. K. (2018). Physicochemical, melting and sensory properties of ice cream incorporating processed ginger (Zingiber Officinale). International Journal of Dairy Technology, 71(1), 190-197. http://dx.doi.org/10.1111/1471-0307.12430.

García-Gómez, B., Romero-Rodríguez, Á., Vázquez-Odériz, L., MuñozFerreiro, N., \& Vázquez, M. (2019). Sensory quality and consumer acceptance of skim yoghurt produced with transglutaminase at pilot plant scale. International Journal of Dairy Technology, 72(3), 388-394.
Hammer, Ø., Harper, D. A. T. T., \& Ryan, P. D. (2001). PAST: paleontological statistics software package for education and data analysis. Palaeontologia Electronica, 4(1), 1-9.

Holzapfel, W. H., Geisen, R., \& Schillinger, U. (1995). Biological preservation of foods with reference to protective cultures, bacteriocins and food-grade enzymes. International Journal of Food Microbiology, 24(3), 343-362. http://dx.doi.org/10.1016/0168-1605(94)00036-6. PMid:7710912.

Jimenez-Flores, R., Klipfel, N. J., \& Tobias, J. (1992). Ice cream and frozen desserts. In Y. K. Hui (Ed.), Dairy science and technology handbook (pp. 59-157). Oxford: Wiley-Blackwell.

Kalicka, D., Znamirowska, A., Pawlos, M., Buniowska, M., \& Szajnar, K. (2019). Physical and sensory characteristics and probiotic survival in ice cream sweetened with various polyols. International Journal of Dairy Technology, 72(3), 456-465. http://dx.doi.org/10.1111/1471-0307.12605.

Marshall, R. T., Goff, H. D., \& Hartel, R. W. (2003). Analyzing frozen desserts. In R. T. Marshall, H. D. Goff \& R. W. Hartel. Ice cream (pp. 295-325). Boston: Springer. http://dx.doi.org/10.1007/978-14615-0163-3_13.

Oliveira, E. W., Esmerino, E. A., Carr, B. T., Pinto, L. P. F., Silva, H. L. A., Pimentel, T. C., Bolini, H. M. A., Cruz, A. G., \& Freitas, M. Q. (2017). Reformulating minas frescal cheese using consumers' perceptions: insights from intensity scales and check-all-that-apply questionnaires. Journal of Dairy Science, 100(8), 6111-6124. http:// dx.doi.org/10.3168/jds.2016-12335. PMid:28551189.

Penna, E. W. (1999). Desarrolho de alimentos para regimenes especiales. In R. H. Morales \& M. V. Tudesca (Ed.), Optimizacion de formulaciones. Santa Cruz de la Sierra: [s.n.].

Santos, B. A., Bastianello Campagnol, P. C., Cruz, A. G., Galvão, M. T. E. L., Monteiro, R. A., Wagner, R., \& Pollonio, M. A. R. (2015). Check All that apply and free listing to describe the sensory characteristics of low sodium dry fermented sausages: comparison with trained panel. Food Research International, 76(Pt 3), 725-734. http://dx.doi. org/10.1016/j.foodres.2015.06.035. PMid:28455058.

Sethi, S., Tyagi, S. K., \& Anurag, R. K. (2016). Plant-based milk alternatives an emerging segment of functional beverages: a review. Journal of Food Science and Technology, 53(9), 3408-3423. http:// dx.doi.org/10.1007/s13197-016-2328-3. PMid:27777447.

Stone, H., \& Sidel, J. L. (1985). Sensory evaluation practices (3rd ed.). Orlando: Academic Pres.

Swagerty, D. L. Jr., Walling, A. D., \& Klein, R. M. (2002). Lactose Intolerance. American Family Physician, 65(9), 1845-1850. PMid:12018807.

Szilagyi, A. (2015). Adult lactose digestion status and effects on disease. Canadian Journal of Gastroenterology \& Hepatology, 29(3), 149-156. http://dx.doi.org/10.1155/2015/904686. PMid:25855879.

Torres, F. R., Esmerino, E. A., Carr, B. T., Ferrão, L. L., Granato, D., Pimentel, T. C., Bolini, H. M. A., Freitas, M. Q., \& Cruz, A. G. (2017). Rapid consumer-based sensory characterization of requeijão cremoso, a spreadable processed cheese: performance of new statistical approaches to evaluate check-all-that-apply data. Journal of Dairy Science, 100(8), 6100-6110. http://dx.doi.org/10.3168/ jds.2016-12516. PMid:28571992.

Trondsen, T., Braaten, T., Lund, E., \& Eggen, A. E. (2004). Consumption of seafood - the influence of overweight and health beliefs. Food Quality and Preference, 15(4), 361-374. http://dx.doi.org/10.1016/ S0950-3293(03)00083-1.

Valentin, D., Chollet, S., Lelièvre, M., \& Abdi, H. (2012). Quick and dirty but still pretty good: a review of new descriptive methods in food science. International Journal of Food Science \& Technology, 47(8), 1-16. http://dx.doi.org/10.1111/j.1365-2621.2012.03022.x. 
Batista et al.

Vicentini, A., Liberatore, L., \& Mastrocola, D. (2016). Functional foods: trends and development of the global market. Italian Journal of Food Science, 28, 338-352.

Vital, A. C. P., Santos, N. W., Matumoto-Pintro, P. T., Scapim, M. R. S., \& Madrona, G. S. (2018). Ice cream supplemented with grape juice residue as a source of antioxidants. International Journal of Dairy Technology, 71(1), 183-189. http://dx.doi.org/10.1111/1471-0307.12412.
Wanasundera, J. P. D., \& Ravindran, G. (1994). Nutritional assessment of Yam (Dioscorea Alata) tubers. Plant Foods for Human Nutrition (Dordrecht, Netherlands), 46(1), 33-39. http://dx.doi.org/10.1007/ BF01088459. PMid:7971785.

World Health Organization - WHO. (2017). Status of the health-related SDGs. In World Health Organization - WHO. World health statistics 2017: monitoring health for the SDGs (pp. 29-35). Geneva: WHO. 